\title{
Cardiovascular basic science in 2020: A view through AATS journals
}

\author{
Manan Desai, MD, Nicolle Ceneri, BS, and Can Yerebakan, MD
}

Basic science research remains at the forefront of innovation and is required to develop novel therapeutic strategies that can be translated to the bedside. Although we continue to refine our surgical technique across the spectrum of congenital heart disease (CHD), we recognize our limitations and have been desperately searching for therapies to complement our efforts in the operating room to further improve patient outcomes.

\section{NEUROPROTECTION IN CONGENITAL HEART DISEASE}

The effect of cyanotic CHD on the developing brain, as well as the use of deep hypothermic circulatory arrest (DHCA) during repair, pose a unique conundrum. Strategies to mitigate the neurodevelopmental deficits that commonly impact children as a result of their cardiac anatomy and necessary operative care are urgently needed. This year, the team of M. Liu and colleagues published important findings in an attempt to demystify the inner workings of microglia and their role as the primary effector of neuroinflammation after exposure to DHCA. ${ }^{1}$ They demonstrated the pathway via which cold-inducible RNA-binding protein (CIRP) exerts its deleterious effects on hippocampus, as demonstrated by the knockout models $\left(\mathrm{CIRP}^{--}\right)$, CIRP inhibitor small interference RNA transfection, and $\mathrm{Brd} 2$ inhibitor JQ1. Their findings are compelling and open up the possibility of a CIRP and Brd2-NF-kB pathway as a novel therapeutic target to prevent detrimental effects of deep hypothermia. ${ }^{2}$ Meanwhile, the group of G. Liu and colleagues have performed complementary work in effort to counter the neuroinflammation and consequential neurodevelopmental deficits that occur specifically in the neonatal period as a result of cyanotic CHD and cardiac surgery. In their study, they used a model with rats reared in chronic hypoxic atmosphere to mimic brain development in human cyanotic neonates. They showed that

From the Division of Cardiac Surgery, Children's National Heart Institute, The George Washington University School of Medicine and Health Sciences, Washington, DC.

Received for publication April 20, 2021; revisions received April 20, 2021; accepted for publication April 21, 2021; available ahead of print May 4, 2021.

Address for reprints: Can Yerebakan, MD, Cardiovascular Surgery, Children's National Hospital, The George Washington University School of Medicine and Health Sciences, 111 Michigan Ave NW, Washington, DC 20010 (E-mail: canyerebakan@hotmail.com).

J Thorac Cardiovasc Surg 2021;162:366-8

0022-5223/ $\$ 36.00$

Copyright $₫ 2021$ Published by Elsevier Inc. on behalf of The American Association for Thoracic Surgery

https://doi.org/10.1016/j.jtcvs.2021.04.084

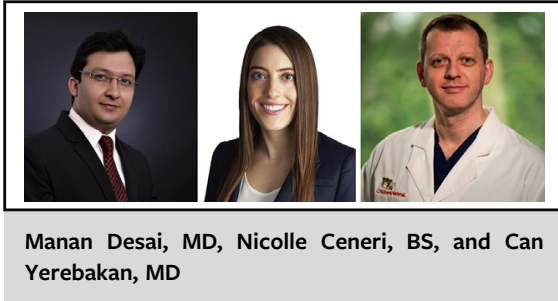

CENTRAL MESSAGE
This article aims to highlight the
most impactful basic science ar-
ticles from the American Asso-
ciation for Thoracic Surgery
journals, with an emphasis on
cardiac regeneration and
neuroprotection.

progesterone had a neuroprotective effect and not only improves brain maturity (ie, better brain weight, less white matter loss, and less ventricular enlargement), which in turn translated into improved motor skills and coordination function, as demonstrated by the Rotarod experiment. ${ }^{3,4}$ They proposed that the neuroprotective effects of progesterone could result from phenotypic switching of microglia from the proinflammatory M1 phenotype to the antiinflammatory M2 phenotype. They also showed that progesterone treatment results in an increased number of mature oligodendrocytes and myelin basic protein expression, a primary constituent of white matter. Taken together, these studies provide unique candidates that demand further exploration by our community so that we may exploit their neuroprotective effects to improve the functional outcomes in our patients with CHD.

\section{CARDIAC REGENERATION}

An important contribution in 2020 was published by Hirose and colleagues, ${ }^{5}$ who proposed a novel perspective to answer the fundamental question as to why cardiac myocytes in human and higher vertebrates quit the cell cycle to enter quiescence. In the new paradigm that they promulgated, as higher vertebrates evolved to transition from ectotherms to endotherms, the cardiac myocytes lost their 
regenerative potential due to inhibition of the cell cycle and regeneration by thyroid hormones, and thus "paid the price for staying warm." The authors connect the dots among increasing cardiac ploidy, decreased cardiac regeneration, increasing thyroid hormones, and improving temperature homeostasis. This new finding has opened a Pandora's box of possibilities particularly regarding potential signaling pathways orchestrating the observed phenomenon.

Sadek and Porrello ${ }^{6}$ weighed in on the "heroic analysis" and described the relevance of thyroid hormone signaling in the field of cardiac regeneration. According to the authors, harnessing this mechanism has the potential to revolutionize the surgical management of heart failure and could be used to reduce scarring following reparative surgery of congenital heart defects. They speculated whether acute signaling modulation would be sufficient to promote cardiac regeneration following injury.

Ryan and Rosengart ${ }^{7}$ were cautiously optimistic of the study's translational potential given an observed clinical discordance: patients with hypothyroidism and concomitant heart failure have increased morbidity and mortality with impaired systolic and diastolic function. Mazine ${ }^{8}$ offered an alternative application of this pathway in the field of human pluripotent stem cell-based cardiac cell therapy.

Applying these findings in future work to generate cardiomyocytes for transplantation may be plausible; however, this continues to pose the same hurdles as current cell-based therapy, such as increased risk of arrythmia by engraftment of immature cells. The way around this obstacle could be cell-free regenerative therapies. An interesting front unfolding in the realm of cardiac regenerative medicine is potential benefits of exosomes derived from cardiosphere-derived cells. Bittle and colleagues ${ }^{9}$ demonstrated preserved systolic function in banded right ventricles in pigs mimicking acute pressure overload. This is a promising area of research that is drawing much attention.
Despite the uphill task of performing research in the year of the pandemic, several groundbreaking discoveries have been made in the areas of neuroprotection in patients with CHD and cardiac regenerative medicine. This has opened up new possibilities, and we earnestly hope that one day these novel therapeutics will be transferred from bench to bedside.

\section{Conflict of Interest Statement}

The authors reported no conflicts of interest.

The Journal policy requires editors and reviewers to disclose conflicts of interest and to decline handling or reviewing manuscripts for which they may have a conflict of interest. The editors and reviewers of this article have no conflicts of interest.

\section{References}

1. Liu M, Li Y, Gao S, Yan S, Zhang Q, Liu G, et al. A novel target to reduce microglial inflammation and neuronal damage after deep hypothermic circulatory arrest. J Thorac Cardiovasc Surg. 2020;159:2431-44.e7.

2. Andersen ND, Alsarraj MK, Turek JW. Commentary: a therapeutic Jedi mind trick: a neuroprotective target to counteract deep hypothermic circulatory arrest 2020;159:2445-6.

3. Liu G, Yan Y, Shi B, Huang J, Mu H, Li C, et al. Benefits of progesterone on brain immaturity and white matter injury induced by chronic hypoxia in neonatal rats. $J$ Thorac Cardiovasc Surg. 2020;160:e55-66.

4. Alsoufi B. Commentary: it's not that we can't find a solution, it's that we can't isolate the problem. J Thorac Cardiovasc Surg. 2020;160:E69-70.

5. Hirose K, Payumo AY, Cutie S, Hoang A, Zhang H, Guyot R, et al. Evidence for hormonal control of heart regenerative capacity during endothermy acquisition. Science. 2019;364:184-8.

6. Sadek HA, Porrello ER. Neonatal heart regeneration: moving from phenomenol ogy to regenerative medicine. J Thorac Cardiovasc Surg. 2020;159:2451-5.

7. Ryan CT, Rosengart TK. Commentary: alas, we are not yet zebrafish. J Thorac Cardiovasc Surg. 2020;159:2457-8.

8. Mazine A. Commentary: harnessing the regenerative potential of the human heart. J Thorac Cardiovasc Surg. 2020;159:2455-6.

9. Bittle GJ, Morales D, Pietris N, Parchment N, Parsell D, Peck K, et al. Exosomes isolated from human cardiosphere-derived cells attenuate pressure overloadinduced right ventricular dysfunction. J Thorac Cardiovasc Surg. September 1, 2020 [Epub ahead of print].

Key Words: basic science, congenital heart disease 


\section{Cardiovascular Basic Science: Recent Articles from AATS Journals}

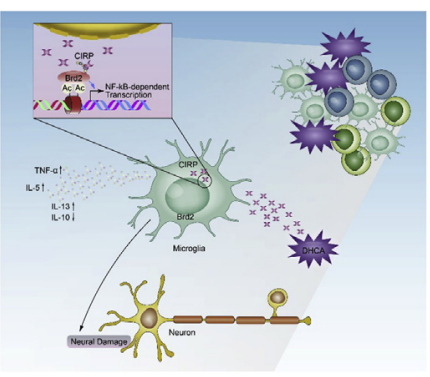

JTCVS: A novel target to reduce microglial inflammation and neuronal damage after deep hypothermic circulatory arrest. Liu M, Li Y, Gao S, Yan S, Zhang Q, Liu G, Ji B. J Thorac Cardiovasc Surg. 2020;159(6):2431-2444.

Commentary: A therapeutic Jedi mind trick: A neuroprotective target to counteract deep hypothermic circulatory arrest. Andersen ND, Alsarraj MK, Turek JW. J Thorac Cardiovasc Surg. 2020;159(6):2445-2446.

Commentary: The brain's response to temperature stress involves shock proteins, RNAbinding proteins and microglia-Should cardiac surgeons care? Ferraris VA. J Thorac Cardiovasc Surg. 2020;159(6):2447-2448.

Commentary: U-CIRP-ing the neurological effects of deep hypothermic circulatory arrest. Sorabella R, Si MS. J Thorac Cardiovasc Surg. 2020;159(6):2449-2450.

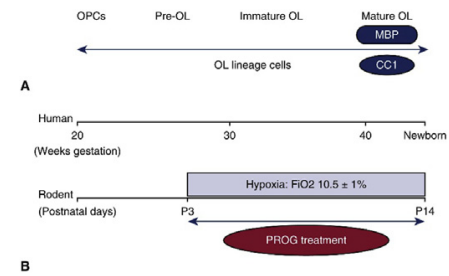

B
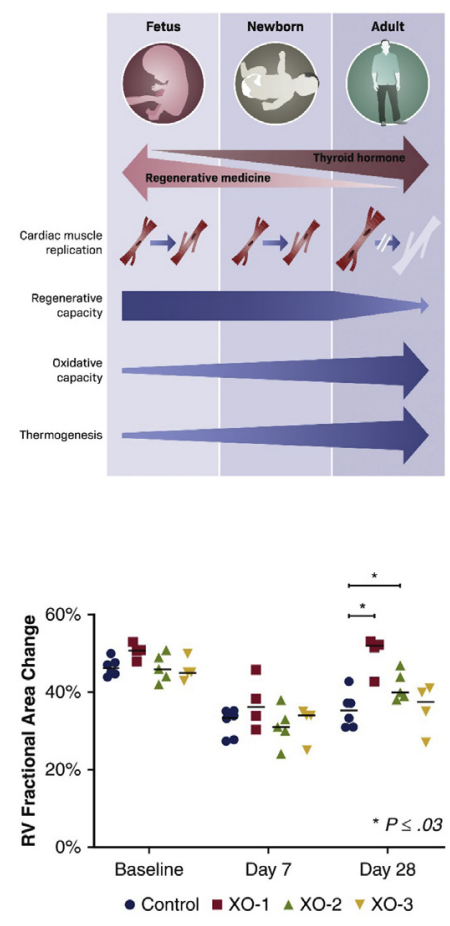

JTCVS: Benefits of progesterone on brain immaturity and white matter injury induced by chronic hypoxia in neonatal rats. Liu G, Yan Y, Shi B, Huang J, Mu H, Li C, Chen H, Zhu Z. J Thorac Cardiovasc Surg. 2020;160(2):55-66.

Commentary: Progesterone the protector? Henn MC, Moon MR. J Thorac Cardiovasc Surg. 2020; 160(2):67.

Commentary: It's not that we can't find a solution, it's that we can't isolate the problem. Alsoufi B. J Thorac Cardiovasc Surg. 2020;160(2):69-70.

JTCVS: Neonatal heart regeneration: Moving from phenomenology to regenerative medicine. Sadek HA, Porrello ER. J Thorac Cardiovasc Surg. 2020;159(6):2451-2455.

Commentary: Harnessing the regenerative potential of the human heart. Mazine A. J Thorac Cardiovasc Surg. 2020;159(6):2455-2456.

Commentary: Alas, we are not yet zebrafish. Ryan CT, Rosengart TK. J Thorac Cardiovasc Surg. 2020;159(6):2457-2458.

JTCVS: Exosomes isolated from human cardiosphere-derived cells attenuate pressure overload-induced right ventricular dysfunction. Bittle GJ, Morales D, Pietris N, Parchment N, Parsell D, Peck K, Deatrick KB, Rodriguez-Borlado L, Smith RR, Marbán L, Kaushal S. J Thorac Cardiovasc Surg. 2021 [In Press].

Commentary: Cardiosphere-derived exosomes for single-ventricle heart disease: Are some of the parts greater than the whole? Vekstein AM, Turek JW, Andersen ND. J Thorac Cardiovasc Surg. 2021 [In Press].

Commentary: Delivering the cargo.... Kumar SR. J Thorac Cardiovasc Surg. 2021 [In Press]. Commentary: An idea with some muscle behind it. Sen DG, Mettler BA. J Thorac Cardiovasc Surg. 2021 [In Press]. 